\title{
Mucopolysaccharidosis type VI (Maroteaux-Lamy syndrome): assessment of joint mobility and grip and pinch strength
}

\author{
Antonio Cardoso-Santos, ${ }^{1}$ Ana C. M. M. Azevedo, ${ }^{2}$ Simone Fagondes, ${ }^{2}$ \\ Maira G. Burin, ${ }^{2}$ Roberto Giugliani, ${ }^{3}$ Ida V. D. Schwartz ${ }^{4}$
}

\begin{abstract}
Objective: To describe the profile of joint mobility and grip and pinch strength of MPS VI patients and to correlate this with urinary excretion of glycosaminoglycans (GAGs), ARSB activity, and the distance covered in a 6-minute walking test (6MWT).

Methods: This was an observational study of 28 patients with MPS VI, who had not undergone specific treatment. All patients were assessed for amplitude of joint mobility (shoulder, elbow, and knee), grip and pinch strength and urinary GAG excretion and also performed the 6MWT.

Results: Shoulder flexion exhibited the greatest limitation, with no correlation with age, followed by knee extension and elbow flexion, both of which were correlated inversely with age. Hand grip strength was compromised in all patients, and pinch strength exhibited a positive correlation with age.

Conclusions: The fact that restricted shoulder flexion was not correlated with age suggests that this finding is present early on in MPS VI and that it constitutes an important clinical sign that should arouse diagnostic suspicion of this disease. The amplitude of knee extension and elbow flexion, in turn, are possible markers of disease progression since they have a negative correlation with age. Further studies are needed to confirm these hypotheses.
\end{abstract}

J Pediatr (Rio J). 2008;84(2):130-135: Mucopolysaccharidosis type VI, joint mobility, muscle strength.

\section{Introduction}

The mucopolysaccharidoses (MPS) are a group of lysosomal diseases caused by a deficiency of one of the enzymes involved in catabolism of glycosaminoglycans (GAGs), which are macromolecules found in the extracellular space and cell membrane. The global incidence of MPS is estimated at 1.3-4.5:100,000 births. ${ }^{1-3}$ This group of diseases is classified according to which enzyme is deficient (Table 1 ). Although each type of MPS exhibits a highly heterogeneous phenotype, symptoms usuallys start in childhood) ${ }^{2}$ and patients exhibit hepatosplenomegaly and cardiac, respiratory, ocular, bone and joint involvement (neurological compromise is variable). Studies undertaken with MPS Brazilian patients suggest both that there is an underdiagnosis of MPS and that the mean age of diagnosis is higher in our country, which prevent families' early access to genetic counseling and specific treatment. ${ }^{4-6}$

MPS type VI (MPS VI) was described for the first time in 1963 and is a type of MPS that is clinically similar to MPS I, but with intelligence preserved and increased urinary excretion of the GAG dermatan sulphate (DS) (Table 1$){ }^{2,7}$ It is an autosomal recessive disease, caused by a deficiency in the activ-

1. Professor assistente, Faculdade de Medicina, Universidade Federal do Rio Grande do Sul (UFRGS), Porto Alegre, RS, Brazil.

2. Doutora.

3. Doutor. Professor titular, Departamento de Genética, UFRGS, Porto Alegre, RS, Brazil.

4. Doutora. Professora adjunta, Departamento de Genética, UFRGS, Porto Alegre, RS, Brazil.

Financial support: BioMarin Pharm. Inc, CNPq and Rede MPS Brazil.

No conflicts of interest declared concerning the publication of this article.

Suggested citation: Cardoso-Santos A, Azevedo AC, Fagondes S, Burin MG, Giugliani R, Schwartz IV. Mucopolysaccharidosis type VI (Maroteaux-Lamy syndrome): assessment of joint mobility and grip and pinch strength. J Pediatr (Rio J). 2008;84(2):130-135.

Manuscript received Jul 16 2007, accepted for publication Oct 172007.

doi:10.2223/JPED.1743 
Table 1 - Mucopolysaccharidosis classification ${ }^{2}$

\begin{tabular}{|c|c|c|c|c|}
\hline Type & Eponym & Enzyme deficiency & $\begin{array}{l}\text { Glycosaminoglycans } \\
\text { excreted in urine }\end{array}$ & Inheritance \\
\hline MPS I & $\begin{array}{l}\text { Hurler } \\
\text { Hurler/Scheie } \\
\text { Scheie }\end{array}$ & $\alpha$-L-iduronidase & ds/hs & $A R$ \\
\hline MPS II & Hunter & Iduronate sulfatase & ds/hs & $X L R$ \\
\hline MPS III & $\begin{array}{l}\text { Sanfilippo A } \\
\text { Sanfilippo B } \\
\text { Sanfilippo C } \\
\text { Sanfilippo D }\end{array}$ & $\begin{array}{l}\text { Heparan } \mathrm{N} \text {-sulfatase } \\
\alpha \text { - } \mathrm{N} \text {-acetylglucosaminidase } \\
\text { Acetyl-coa- } \alpha \text {-glucosaminide } \\
\text { Acetyltransferase } \\
\mathrm{N} \text {-acetylglucosamine -6-sulfatase }\end{array}$ & hs & AR \\
\hline MPS IV & $\begin{array}{l}\text { Morquio A } \\
\text { Morquio B }\end{array}$ & $\begin{array}{l}\text { Galactosamine-6-sulfatase } \\
\beta \text {-galactosidase }\end{array}$ & $\begin{array}{c}\text { ks/ chondroitin 6-sulphate } \\
\text { ks }\end{array}$ & $\begin{array}{l}A R \\
A R\end{array}$ \\
\hline MPS VI & Maroteaux-Lamy & $\begin{array}{l}\mathrm{N} \text { - acetylgalactosamine } \\
4 \text {-sulfatase }\end{array}$ & ds & AR \\
\hline MPS VII & Sly & $\beta$-Glucuronidase & ds/hs/chondroitin 4-,6-sulphate & $A R$ \\
\hline MPS IX* & Natowicz & Hyaluronidase & Hyaluronic acid & $A R$ \\
\hline
\end{tabular}

$\overline{\mathrm{AR}}=$ autosomal recessive; $\mathrm{ds}=$ dermatan sulphate; hs = heparan sulphate; $\mathrm{ks}=$ keratan sulphate; MPS = mucopolysaccharidoses; XLR = X-linked recessive.

* Just one patient has been described in the literature.

ity of the lysosomal hydrolase $\mathrm{N}$-acetylgalactosamine 4-sulfatase, or arylsulfatase B (ARSB), coded by the ARSB gene which is located on chromosome $5 q 13-14 .{ }^{5}$ It would appear that MPS VI is one of the rarest types of MPS, ${ }^{1,3}$ but in Brazil this situation is different, since here this is one of the most often diagnosed types of MPS. ${ }^{8,9}$ The causes of this finding are not yet known. Patients with MPS VI usually appear normal at birth, but occasionally may present characteristics such as dolicocephaly, wide forehead and spinal abnormalities. As the disease progresses, and depending on the severity of the case, they will develop abnormalities in a range of different organs and tissues. These may include facial infiltration, hepatosplenomegaly, growth deficit, joint contractures, cardiovascular involvement, ocular abnormalities (corneal clouding, glaucoma and papilledema with optical atrophy), neurological involvement (hydrocephalus, medullar compression; mental retardation is not a common occurrence), obstructive sleep apnea syndrome and umbilical and inguinal hernias. ${ }^{2}$ Osteoarticular manifestations, which are the subject of this study, are generally secondary to metaphyseal involvement and thickening and fibrosis of the articular capsule. ${ }^{10}$ They are progressive changes that limit movements, ${ }^{7}$ and in some joints, especially knees, hips and elbows, limitations are present from the first years of life onwards. ${ }^{2,7}$ Flexional contractures in the fingers give them a claw-like appearance $^{2}$ (Figure 1). The emergence of carpal tunnel syndrome, due to compression of the median nerve at the wrist by deposits of GAGs, and/or Dupuytren's contractures affect hand movements, including the ability to grasp objects and to pinch. ${ }^{7}$ In conjunction, these abnormalities contribute to a significant inability to perform simple acts necessary to daily life, such as feeding oneself, dressing and performing personal hygiene, and to accomplish practical tasks such as opening doors, answering telephones, catching the bus, etc. With relation to treatment, hematopoietic cell transplantation (HCT) is a strategy which risk/benefit is not well-established. Enzyme replacement therapy (ERT) has shown itself to be a potential strategy for the treatament of some MPS, with encouraging results, but long-term follow-up is still needed. ${ }^{11-14}$

The principal objective of this study was to describe the profile of the joint mobility, based on the assessment of specific joints (shoulders, elbows and knees), and to evaluate the grip and digit to digit and lateral pinch strength of a group of patients with MPS VI who had not previously been treated with ERT or HCT. The secondary objectives were to assess the correlations between mean joint mobility scores, grip strength and pinch strength and age, urinary GAG excretion, ARSB activity and performance in the 6-minute walking test (6MWT).

\section{Methods}

This study was approved by the National Research Ethics Commitee (CONEP - Comissão National de Ética em Pesquisa) and meets all of the clinical research regulations, including the informed consent. In order to be included in the study, patients had to have a diagnosis of MPS VI confirmed 


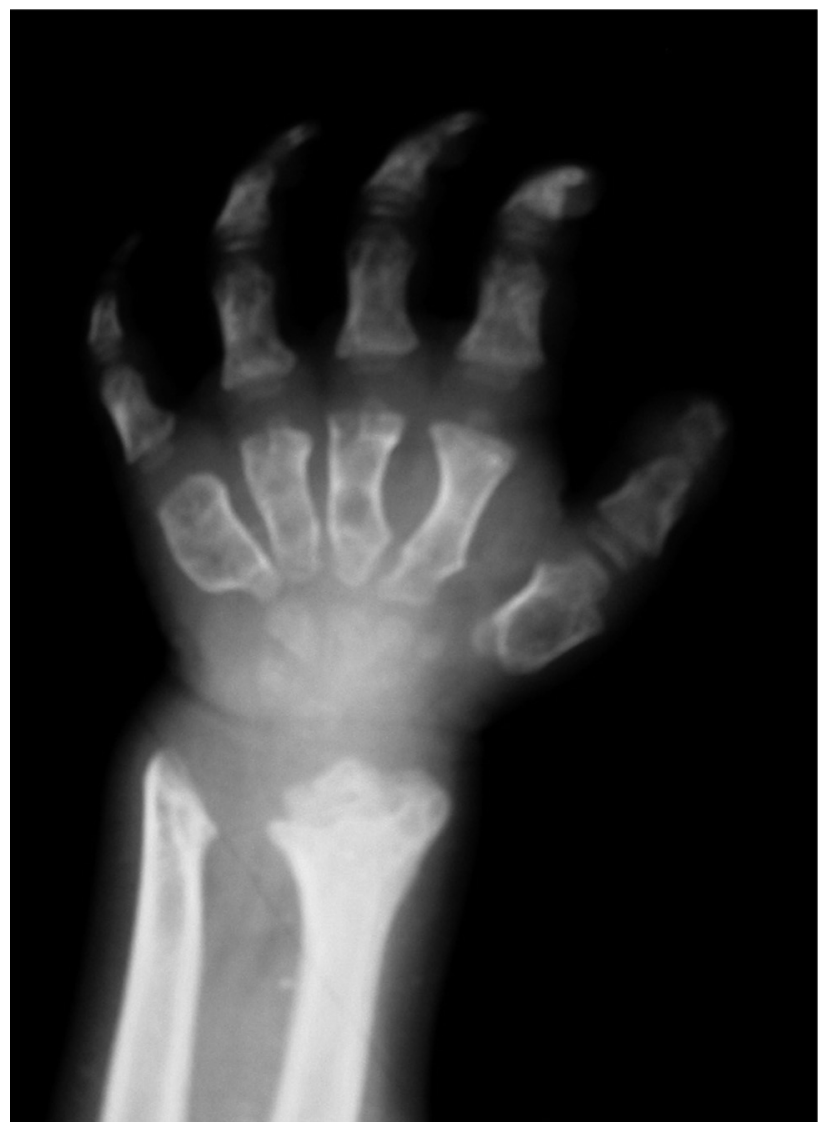

Figure 1 - Radiography of the hand of a 14-year-old patient with Mucopolysaccharidosis VI, showing findings typical of these patients (claw hand, shortened metacarpals and phalanges, pointed proximal portion of the metacarpals, increase in the angle of the distal radius in relation to the ulna)

by deficient activity of ARSB in leukocytes or fibroblasts (with at least one other normal sulfatase, in order to exclude multiple sulfatase deficiency), and must not have received HCT or ERT treatment.

The study sample originated from the MPS clinics at the Medical Genetics Service at the Hospital de Clínicas de Porto Alegre, Brazil, which is an international reference center for the diagnosis and treatment of MPS. All assessments were carried out during the same consultation, and the physiatric assessment (joint mobility, grip and pinch strength) was always carried out by the same examiner (ACS), a physiatric physician with a great breadth of experience in MPS.

\section{Joint mobility assessment (JMA)}

The passive JMA was evaluated by standardized techniques, ${ }^{15,16}$ investigating flexion and extension of the shoulders, elbows (Figure 2) and knees, using a goniometer. Three consecutive measurements were made for each joint and the mean value taken. The results from the left and right sides were compared (Student's $t$ test for paired samples) and,

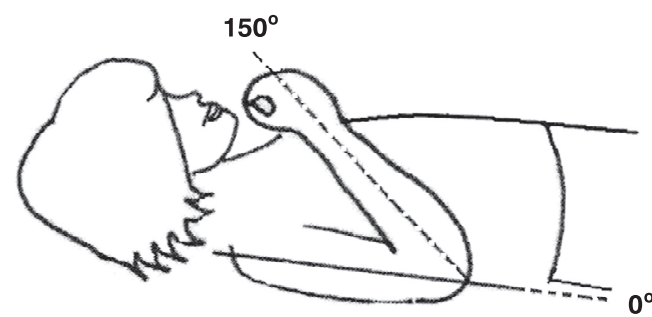

Normal elbow flexion from $0^{\circ}$ to $150^{\circ}$.

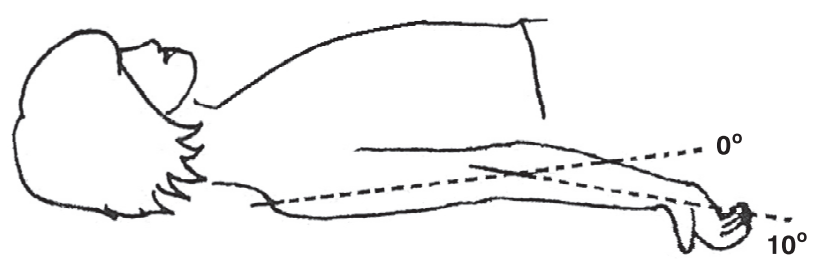

Normal elbow flexion does not pass $0^{\circ}$.

The figure ilustrates overextension.

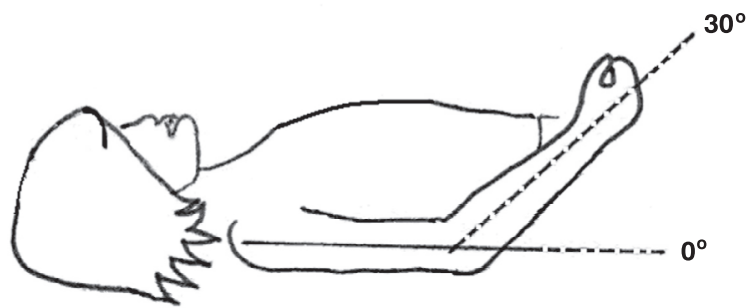

When the patient is unable to reach $0^{\circ}$, this is defined as negative extension (in this case $-30^{\circ}$ ).

Figure 2 - Joint mobility assessment (JMA) - elbow

when there was no difference between them, their mean was taken.

\section{Pinch strength assessment (digit to digit and lateral pinch)}

A B\&L Mechanical pinch dynamometer, scaled in pounds, was used to assess pinch strength of the 1st. and 2 nd digits (digit to digit and lateral pinch). In order to take this measurement the elbow had to be at $90^{\circ}$, and the forearm and wrist in a neutral position. Three measurements were taken of each pinch strength and the mean of each taken. The results from the left and right sides were compared (Student's $t$ test for paired samples) and, when there was no difference between them, their mean was taken.

\section{Grip strength assessment (manual pressure)}

A manual, hydraulic dynamometer, Jamar brand, was employed in this study to measure and grip strength, according to a standardized technique. Three measurements were 
Table 2 - Joint mobility (passive) of the study sample $(n=26 / 28)$

\begin{tabular}{lccc}
\hline & Shoulder* & Elbow* & Knee* \\
\hline Extension $\left({ }^{\circ}\right)^{+}$ & $\bar{X}=53.5$ (normal: 60$)$ & $\bar{X}=-23.1$ (normal: 0$)$ & $\bar{X}=-29.2$ (normal: 0$)$ \\
& Range $=39$ to 63 & Range $=-50$ to +20 & Range $=-55.0$ to 17.5 \\
Flexion $\left({ }^{\circ}\right)^{+}$ & $\mathrm{SD}= \pm 5.7$ & $\mathrm{SD}= \pm 13.2$ & $\mathrm{SD}= \pm 14.2$ \\
& $\bar{X}=80.7$ (normal: 180$)$ & $\bar{X}=126.7$ (normal: 150$)$ & $\bar{X}=121.8($ normal: 135$)$ \\
& Range $=54$ to 136 & Range $=100.0$ to 146.5 & Range $=102.5$ to 135.5 \\
SD $= \pm 17.4$ & SD $= \pm 11.1$ & $S D= \pm 9.2$
\end{tabular}

* Three measurements were taken for each joint movement and the mean taken as the final result. There was no difference between the left and right sides and so the figures given here are means of both sides.

${ }^{+}$Normal values are according to the American Academy of Orthopedic Surgeons. ${ }^{20}$

taken for each hand, with 20 second rest intervals, and the mean taken. The results from the left and right sides were compared (Student's $t$ test for paired samples) and, when there was no difference between them, their mean was taken.

\section{Urinary GAG assays}

Random urine samples were analysed, as described by Jong et al. ${ }^{17}$

\section{Measurement of ARSB activity in leukocytes}

It was performed as described by Kresse et al. ${ }^{18}$

\section{Six-minute walking test (6MWT)}

Performed according to the American Thoracic Society guidelines. ${ }^{19}$ Two tests were performed on different days and the mean taken for analysis.

\section{Results}

Twenty-eight patients were enrolled on the study (males: 15; females: 13). None of the patients reported having received, during the year prior to the study, rehabilitation therapy on a regular basis (at least one session per week). Mean age at assessment was 8.1 years $(S D=2.9$ years; range = 4- 15.5 years). As expected, all patients exhibited reduced ARSB activity in leukocytes ( $\bar{X}=5.4$ nanomol/hour/mg prot; $\mathrm{SD}=3$; range $=0-13$; normal range $=72-176)$, and elevated levels of urinary GAG $(\bar{X}=43.1 \mathrm{mg} / \mathrm{mmol}$ creat; $\mathrm{SD}=14.6$; range $=17-78 ;$ normal range $=<12$ if age below 9 years,$<7$ if age between 9 and 19 years). The mean distance covered in the 6MWT was $258.5 \mathrm{~m}$ (SD $=78$; range $=82-420)$. No significant correlation was detected between ARSB activity or urinary GAG and the distance covered in the 6MWT.

It was not possible to carry out the strength and JMA measurements in two cases, due to a lack of co-operation on the part of the patients. Analysis of the JMA detected, in descending order of severity, major compromise to shoulder flexion, knee extension, elbow flexion, elbow extension, shoulder extension and knee flexion (Table 2 ). A negative correlation was found between age and degree of elbow flexion $(r=-0.44$; $p=0.026)$, age and degree of knee extension $(r=-0.56, p=$ $0.003)$, and a positive correlation between shoulder flexion and the distance covered in the 6MWT $(r=0.49, p=0.01)$.

Grip strength was zero in 23 of the 26 patients assessed, since either strength or joint mobility were insufficient to activate the dynamometer. The three patients who did manage to activate the equipment reached levels well below normal (a mean of 0.1 pounds). Mean normal values are between 28.6 pounds (age 6-7 years) and 64.4 pounds (age $14-15$ years). ${ }^{21}$

Mean digit to digit and lateral pinch strengths were 2.7 pounds $(S D=0.9 ;$ range $=1.4-5.0$ ) and 3.5 pounds $(S D=$ 1.2 ; range $=1.7-5.7$ pounds), respectively. A positive correlation was observed between age and digit to digit pinch strength $(r=0.448, p=0.022)$, and between age and lateral pinch strength $(r=0.593, p=0.001)$.

The sample's pinch strength loss ratio was calculate, giving a result of $35.5 \%(S D=11.6$; range $=35.8-79.8)$ for digit to digit pinch strength and $27 \%(\mathrm{SD}=8.1$; range $=57.1-85.7)$ for lateral pinch strength; there was no statistically significant difference between males and females in terms of loss of digit to digit pinch strength ( $p=0.4$ ) or of lateral pinch strength $(p=0.3)$. The correlations between these digit to digit and lateral pinch loss ratios and urinary GAG levels, ARSB activity and 6MWT performance were not significant.

No correlation was found between the JMA of the joints assessed and grip and pinch strength measurements, or between JMA and grip and pinch strength and urinary GAG excretion, enzyme activity (ARSB) and 6MWT performance.

\section{Discussion}

Studies of the mobility and strength profiles of MPS VI patients, and those with MPS in general, are scarce and those that do exist employ these variables as measures of treatment outcomes (ERT or HCT). ${ }^{11,13,14,22-24}$ Therefore, the information provided by this study is of relevance, especially to future studies that aim to assess the impact of specific treatments for MPS VI on the osteoarticular system. 
Shoulder flexion was the movement most compromised in MPS VI, but there was no correlation with age. In these patients, this finding may be secondary to severe limitation of shoulder flexion right from the very first years of life. If this is the case, then involvement of this joint is an important clinical signal that should arouse a diagnostic suspicion of MPS VI, but it is not a marker of disease progression. In contrast, knee extension and elbow flexion measurements demonstrated a negative correlation with age (the JMA of these joints detected worse mobility among older patients), and are possibly markers of MPS VI progression. It is important to emphasize that compromise to these three joints prejudices the execution of daily activities such as brushing teeth and hair, feeding oneself and walking itself.

The positive correlation between degree of shoulder flexion and the distance covered in the 6MWT may be due to associated movements (swinging) of the upper limbs while walking. Therefore, patients who can walk further would have less shoulder flexion compromise.

The fact that the grip strength of 23 of the 26 patients was zero reflects the major involvement of finger flexion that is associated with MPS VI. However, another possible cause could be the use of an inappropriate dynamometer which is unable to measure small displacements of the fingers. In contrast, the compromised finger joint mobility did not impede pinch movements, neither digit to digit nor lateral pinch, despite major deficits in strength and mobility, and there was a positive correlation between age and both digit to digit and lateral pinch strengths (strength was greatest in the oldest patients, despite being well below normal values). This, therefore, is one possible outcome that could be assessed in future research.

We believe studies that have the objective of delineating the natural history of MPS and which employ accessible methods that are reproducible and sensitive, such as the ones used in this study, should continue to be carried out. It is only thus that better markers, both of disease progression and for monitoring the effects of drug and rehabilitation treatments, can be defined.

\section{Acknowledgements}

We are grateful to BioMarin Pharm. Inc, the CNPq and the Rede MPS Brasil for supporting this project.

\section{References}

1. Meikle PJ, Hopwood JJ, Clague AE, Carey WF. Prevalence of lysosomal storage disorders. JAMA. 1999;281:249-54.

2. Neufeld E, Muenzer J. The mucopolysacharidoses. In: Scriver $C$, Beandet A, Sly S, Valle D, Childs B, Kinzler K, et al., editors. The metabolic and molecular basis of inherited diseases. 8th ed. New York: McGraw-Hill; 2001. p. 342152.
3. Poorthuis BJ, Wevers RA, Kleijer WJ, Groener JE, de Jong JG, van Weely $S$, et al. The frequency of lysosomal storage diseases in The Netherlands. Hum Genet. 1999;105:151-6.

4. Pinto LL, Schwartz IV, Puga AC, Vieira TA, Munoz MV, Giugliani R. Prospective study of 11 Brazilian patients with mucipolysaccharidosis II. J Pediatr (Rio J). 2006;82:273-8.

5. Azevedo AC, Schwartz IV, Kalakun L, Brustolin S, Burin MG, Beheregaray AP, et al. Clinical and biochemical study of 28 patients with mucopolysaccharidosis type VI. Clin Genet. 2004; $66: 208-13$.

6. Schwartz IV, Ribeiro MG, Mota JG, Toralles MB, Correia P, Horovitz D, et al. A clinical study of 77 patients with mucopolysaccharidosis type II. Acta Paediatr Suppl. 2007;96: 63-70.

7. Nyhan W, Ozand P. Maratoux-Lamy disease Mucopolysaccharidoses VI (MPS VI) / $\mathrm{N}$-Acetylgalactosamine-4-sulfatase deficiency. In: Nyhan W, Ozand $\mathrm{P}$, editors. Atlas of metabolic diseases. London: Chapman \& Hall; 1998. p. 47781.

8. Azevedo AC Estudo clínico e bioquímico de 28 pacientes com mucopolissacaridose tipo VI [dissertação]. Porto Alegre: Universidade Federal do Rio Grande do Sul; 2004.

9. Coelho JC, Wajner M, Burin MG, Vargas CR, Giugliani R. Selective screening of 10,000 high-risk Brazilian patients for the detection of inborn errors of metabolism. Eur J Pediatr. 1997; 156:650-4.

10. Schwartz I, Matte $U$, Leistner $S$, Giugliani R. Mucopolissacaridoses. In: Carakushanski G, editor. Doenças genéticas em pediatria. Rio de Janeiro: Guanabara Koogan; 2001. p. 1804.

11. Harmatz P, Ketteridge D, Giugliani R, Guffon N, Teles EL, Miranda $M C$, et al. Direct comparison of measures of endurance, mobility, and joint function during enzyme-replacement therapy of mucopolysaccharidosis VI (Maroteaux-Lamy syndrome): results after 48 weeks in a phase 2 open-label clinical study of recombinant human $\mathrm{N}$-acetylgalactosamine 4 -sulfatase. Pediatrics. 2005;115:e681-9.

12. Harmatz P, Giugliani R, Schwartz I, Guffon N, Teles EL, Miranda MC, et al. Enzyme replacement therapy for mucopolysaccharidosis VI: a phase 3, randomized, double-blind, placebo-controlled, multinational study of recombinant human $\mathrm{N}$-acetylgalactosamine 4-sulfatase (recombinant human arylsulfatase B or rhASB) and follow-on, open-label extension study. J Pediatr. 2006;148:533-9.

13. Sifuentes M, Doroshow R, Hoft R, Mason G, Walot I, Diament M, et al. A follow-up study of MPS I patients treated with laronidase enzyme replacement therapy for 6 years. Mol Genet Metab. 2007; 90:171-80.

14. Cox-Brinkman J, Smeulders MJ, Hollak CE, Wijburg FA. Restricted upper extremity range of motion in mucopolysaccharidosis type I: no response to one year of enzyme replacement therapy. J Inherit Metab Dis. 2007;30: 47-50.

15. Gajdosik RL, Bohannon RW. Clinical measurement of range of motion. Review of goniometry emphasizing reliability and validity. Phys Ther. 1987;67:1867-72.

16. Riddle DL, Rothstein JM, Lamb RL. Goniometric reliability in a clinical setting. Shoulder measurements. Phys Ther. 1987;67: 668-73.

17. de Jong JG, Wevers RA, Liebrand-van Sambeek R. Measuring urinary glycosaminoglycans in the presence of protein: an improved screening procedure for mucopolysaccharidoses based on dimethylmethylene blue. Clin Chem. 1992;38:803-7. 
18. Kresse H, von Figura K, Klein U, Glossl J, Paschke E, Pohlmann R. Enzymic diagnosis of the genetic mucopolysaccharide storage disorders. Methods Enzymol. 1982;83:559-72.

19. ATS Committee on Proficiency Standards for Clinical Pulmonary Function Laboratories. ATS statement: guidelines for the six-minute walk test. Am J Respir Crit Care Med. 2002;166: 111-7.

20. Delisa JA. Medicina de reabilitação: princípios e práticas. São Paulo: Manole; 1992.

21. Mathiowetz V, Wiemer DM, Federman SM. Grip and pinch strength: norms for 6- to 19-year-olds. Am J Occup Ther. 1986; 40:705-11.

22. Weisstein JS, Delgado E, Steinbach LS, Hart K, Packman S. Musculoskeletal manifestations of Hurler syndrome: long-term follow-up after bone marrow transplantation. J Pediatr Orthop. 2004;24:97-101.
23. Tokic V, Barisic I, Huzjak N, Petkovic G, Fumic K, Paschke E. Enzyme replacement therapy in two patients with an advanced severe (Hurler) phenotype of mucopolysaccharidosis I. Eur ] Pediatr. 2007;166:727-32.

24. Lee V, Li CK, Shing MM, Chik KW, Lam CW, Tsang KS, et al. Umbilical cord blood transplantation for Maroteaux-Lamy syndrome (mucopolysaccharidosis type VI). Bone Marrow Transplant. 2000;26:455-8.

Correspondence:

Antonio Cardoso-Santos

Rua Schneider, 797

CEP 91787-190 - Porto Alegre, RS - Brazil

Tel.: +55 (51) 3264.2721

E-mail: acsantos@hcpa.ufrgs.br 